African J. Biol. Sci., 14 (2): 141-150 (2018)

ISSN 1687-4870

e- ISSN 2314-5501 (online)

www. ajbs.journals.ekb.eg

E.mail: aasdjournal@yahoo.com

\title{
Biochemical and nutritional studies on cocoa powder and its effect on blood lipids in experimental rats
}

\author{
Suzan A. Saad \\ Nutrition and Food Science Department, Faculty of Home Economics, Al- Azhar Univ.
}

\begin{abstract}
Cocoa powder considered a high rich source of polyphenols so it reduce the lipid profile in blood and the risk of cardiovascular disease. The present investigation aimed to assess the biochemical and nutritional properties on cocoa powder and its effect on blood

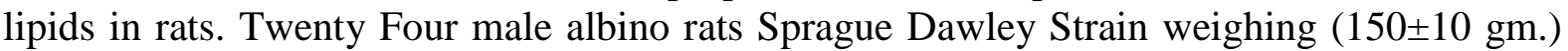
used in experiment. All rats were fed on basal diet (one week) for adaptation. Then randomly divided into two main groups as following : The first main group include: (G1) fed on basal diet as a control negative group (-ve). The second main group was fed on high fat diet (HFD) for (4weeks) to induce hyperlipidemia. Then, rats were divided into three groups as following: (G2) fed on high fat diet as a positive control group (+ve), (G3,G4), were fed high fat diet supplemented with cocoa powder $(5 \%, ! 0 \%$ respectively). The results indicated a significant decrease in BW, FI, and FER in rats fed with basil diet + cocoa powder nearly from negative control group (-ve). (HFD) rats showed a significant increase in serum total cholesterol, triglycerids, LDL-c, VLDL-c, compared to negative control group(-ve). On the other hand, (HFD) rats showed a significant decrease in serum high-density lipoproteins (HDL-c) compared to normal control group (-ve). While cocoa powder improve lipids profile and protective from cardiovascular risk .
\end{abstract}

Keywords: Cocoa powder, Hyperlipidemia, total cholesterol, triglycerids and lipoproteins.

\section{INTRODUCTION}

Atherosclerosis is considered as a low- grade chronic inflammatory process resulting from interaction between plasma lipoprotein, cellular components and the extrcellular matrix of the arterial wall (Tedgui and Mallat , 2006). Cardiovascular disease (CVD), as a group, is a leading cause of death in the United States and worldwide, causing over 16.7 million deaths globally in 2002. (Mackay and Mensah, 2004). Atherosclerosis is crucial to (CVD) and is strongly related to dyslipidemia. Classically, dyslipidemia includes high total cholesterol, high lowdensity lipoprotein (LDL) cholesterol, low high-density lipoprotein (HDL) cholesterol and high triglycerides (Abuzaid and AlMenyar, 2015). Studies suggest CVD diseases may be preventable by lifestyle modification, such as exercise and nutrition (Tanasescu et al., 2002; Weisburger, 2000; Stampfer et al., 2000).
Nowadays, there is growing interest in the use of plant foods for the prevention and management of CVD and other related disorders, with a special emphasis on cocoa and its products (Arranz et al., 2013). Fruits, vegetables, tea and chocolate are major sources of antioxidants, flavonoids, which have been shown to have protective effects against CDV (Eyre et al., 2004; Goldstein et al ., 2001) . Cocoa products contain greater antioxidant capacity and greater amount of flavonoids per serving than all others sources, it is important to explore chocolate's potential effects on CVD (Baltimore et al., 1996, Kris-Etherton and Keen, 2002). Cocoa (Theobroma cacao L.) is one of the most ancient cultivated human crops. It is originated in Mexico and is central to the local diet (Colombo et al., 2012). Consumption of cocoa is related to higherquality diets, including higher intakes of protein, antioxidants and a number of vitamins and mineral elements. Cocoa 


\section{Suzan A. Saad}

intake is also associated with several beneficial health effects, particularly reduced risks of obesity, diabetes, hypertension and CVD (Sentürk and Günay, 2015; Hooper et al., 2012). Cocoa bean is loaded with the polyphenols such as quercetin (including its glucoside), clovamide, deoxyclovamide and procyanidin, Epicatechin, catechin) (Sanbongi et al., 1998; Hammerstone, 1999 ). Research indicates that the flavonoids, a class of polyphenols, has antioxidant characteristics with potential health benefits that may reduce the risk of cardiovascular disease and cancer (Allen $e t$ al., 2008). The specific antioxidants in chocolate (i.e., cocoa flavanols) include catechin and epicatechin, which are single flavanol molecules structurally similar to the antioxidants found in grapes and tea (Arts and Hollman, 2005).

Cocoa also appears to have antiaging and anti-inflammatory properties. Cocoa is a good source of the minerals magnesium, sulphur, calcium, iron, zinc, copper, potassium, and manganese; plus some of the B Vitamins. Cocoa enhanced clot prevention afforded by cocoa flavanols (Rein et al ., 2000 ).

In general, most of the nutritional and clinical studies linking cocoa with CVD have been mainly devoted to the effects of bioactive components such as polyphenols and flavonoids, and have often paid little or no attention to the cocoa fat as a possible mechanism for explaining such link. In fact, fats are the highest variable components of the diet both in quantitative and in qualitative terms, and they are the most relevant dietary factor affecting serum lipids, especially in cases with dyslipidemia (Galli, 2012). Nevertheless, controlled human or animal studies that link consumption of defatted cocoa and cholesterol with serum lipids and lipoproteins in particular are generally lacking.

Previous studies have suggested that dark chocolate consumption reduces blood pressure (Grassi et al., 2005b;
Grassi et al., 2008), improves insulin sensitivity as shown by significantly higher QUICKI (quantitative insulin sensitivity check index) measurements (Grassi et al., 2008), improves vascular endothelial function and reverses vascular dysfunction (Engler et al., 2004; Grassi et al., 2005; Wang-Polagruto et al., 2006), reduces insulin resistance as evidenced by significantly lower HOMA-IR (homeostasis model assessment of insulin resistance) (Grassi et al., 2005).

The present investigation aimed to assess the improvement role of cocoa powder on body weight and biochemical parameters of hyperlipidemic rats.

\section{MATERIALS AND METHODS: Materials:}

-Cocoa powder : was purchased from local market Tanta City, Elgharbia Governorate, Egypt.

- Casein, choline chloride and DLmethionine, vitamins and salt mixture were obtained from El -Sharkiya Co., Sun flower oil and corn starch also were obtained.

Animals: Male albino rats $(n=24)$ of Sprague Dewey Strain weighting (150 $\pm 10 \mathrm{~g} g \mathrm{gm})$ were obtained from the animal colony, Helwan farm, Vaccine and Immunity Organization, Ministry of Health, Helwan Governorate, Egypt. Rats were kept in single wire cages with wire bottoms under hygienic conditions. The diet was introduced to the rats in special food containers to avoid scattering of food. Also water supply was given ad-libitum and check daily. The rats fed basil diet for one week as adaption period .Standard diet was prepared from fine ingredients per $100 \mathrm{~g}$.

- Kits were purchased from Egyptian American Company for Laboratory Service and Supplied by Alkan Company.

\section{Methods :}

\section{Chemical analysis:}

Cocoa powder was subjected to chemical analysis to determine: Total phenols; 

experimental rats

phenolic compounds were determined by HPLC according to method of Goupy et al. (1999) at central lab of food technology research Institute Agric. Res. Cent. Egypt.

\section{Experiment design:}

Twenty four male Sprague-Dawley Albino rats( $150+10 \mathrm{gm}$ ) were acclimatized for one week, fed basal diet according to Reeves et al.,(1993) and water ad libitum. Rats divided into two main groups as following:

- The first main group (G1): rats fed on basal diet as a control negative group (v-).

- The second main group was fed on high fat diet (HFD) for (4 weeks) to induce hyperlipidemia. Then, rats were divided into three groups as following:

- (G2) fed on high fat diet as a positive control group $(\mathrm{v}+)$,

- (G3, G4) fed high fat diet supplemented with cocoa powder $(5 \%, 10 \%$, respectively).

At the end of experiment (28) days, rats were be deprived of food and water overnight before being sacrificed. Blood samples were collected in dry centrifuge tubs from hepatic portal veins. Serum samples were separated by centrifugation at $4000 \mathrm{rpm}$ for 10 minutes and kept in plastic vial at -20 till analysis.

\section{- Determination of some Biological parameters:}

During the experimental period, the diet consumed was recorded every day, and body weight recorded every week. The body weight gain (BWG \%) and feed efficiency ratio (FER) were determined according to Champman et al. (1959).

\section{-Biochemical analysis of serum:}

The serum samples was separated to estimate some biochemical parameters, i.e. total cholesterol and Triglycerides according to Fossati and Prancipl (1982). Very Low Density Lipoprotein Cholesterol (VLDL $-\mathrm{c}$ ) according to the equation of Friedewald et al. (1972). HDL cholesterol was determined according to the method described by Burstein 2017), the concentration of LDL was estimated according to the equation of Friedewald $e t$ al. (1972).

\section{Statistical analysis:}

The obtained data was statistically analyzed by SPSS computer software. The calculated was occurred by analysis of variance ANOVA and follow up test LSD by SPSS according to Armitage and Berry (1987).

\section{RESULTS}

The macronutrients composition of cocoa powders used in this study is given in table I. cocoa powder was found to contain low content of fat (13.7 g/100), high content of carbohydrates ( 57.9 $\mathrm{g}$ ). The amount of protein is ( $16.6 \mathrm{~g}$ ). Also, cocoa is a good source of the minerals magnesium, sulphur, calcium, iron, zinc, copper, potassium, and manganese; plus some of the B Vitamins.

Table 1: Nutrition consumption of cocoa powder ( per 100 gram ):

\begin{tabular}{|l|l|}
\hline Parameter & Kcal / Gm \\
\hline Calories (Kcal) & 400 \\
\hline Total carbohydrates (g) & 57.9 \\
\hline Starch (g) & 6.4 \\
\hline Dietary fiber (g) & 33.2 \\
\hline Total fat (g) & 13.7 \\
\hline SFA (g) & 8.1 \\
\hline MUFA (g) & 4.6 \\
\hline PUFA (g) & 0.4 \\
\hline Cholesterol (mg) & 0.0 \\
\hline Proteins (g) & 19.6 \\
\hline magnesium & $125 \%$ \\
\hline calcium & $13 \%$ \\
\hline iron & $77 \%$ \\
\hline zinc & $45 \%$ \\
\hline copper & $189 \%$ \\
\hline potassium & $44 \%$ \\
\hline manganese & $192 \%$ \\
\hline \multicolumn{2}{|c|}{ The total phenolic and total } \\
proanthocyanidin content of the cocoa \\
powder was determined by Bathee Smith \\
methods (Andres-Lacueva et al., 2013). \\
Singletonand Rossi, 2000). Individualized
\end{tabular}


phenolic compounds were determined by HPL-c analysis of cocoa powder. The major Individualized phenolic components are Epicatechin (46.08) followed by Procyanidin B2 $(36.54 \mathrm{mg} / \mathrm{g})$. While the lowest compounds are Quercetin-3glucuronide (0.10). Cocoa powder contains high amounts of total polyphenols $(495.2 \mathrm{mg} / \mathrm{g})$ and total proarthocyanidins $(425.7 \mathrm{mg} / \mathrm{g})$.

Table (2): Phenolic compounds in cocoa powder (ppm).

\begin{tabular}{|l|l|}
\hline Flavans $\quad$ Mean value \\
\hline Catechin & 10.41 \\
\hline Epicatechin & 46.08 \\
\hline Procyanidin B2 & 36.54 \\
\hline Isoquercetrin & 2.23 \\
\hline Quercetin & 0.22 \\
\hline Quercetin-3-arabinoside & 0.70 \\
\hline Quercetin-3-glucuronide & 0.10 \\
\hline Total polyphenols & 495.2 \\
\hline Total proanthocyanidins & 425.7 \\
\hline
\end{tabular}

\section{Biological evaluation}

Data presented in Table (3) showed the effect of cocoa powder on feed intake (FI) and body weight gain (BWG\%) in hyperlipidemic rats . The results revealed that rats reserved supplemented diet with cocoa powder demonstrated no significant p>0,05 in the mean value of feed intake as compared to negative control (-ve). Positive control group (+ve) recorded significant $(\mathrm{P}>0.05)$ increase in $\mathrm{BWG} \%$ comparing to negative control group (-ve). While, rats reserved supplemented diet with cocoa powder showed clear significant $(\mathrm{P}>0.05)$ decrease in BWG \% compared to the positive control group (+ve).

Table 3: Mean values \pm SD of feed intake (g/d) and BWG\% of control rats and treated groups $(n=24)$

\begin{tabular}{|l|l|l|}
\hline Group Parameter & Feed intake & BWG\% \\
\hline Normal control (-ve ) & $15.67 \pm 1.0^{\mathbf{c}}$ & $15.3 \pm 1.09^{\mathrm{a}}$ \\
\hline Positive control (+ve) & $14.27 \pm 1.0^{\mathrm{a}}$ & $35.15 \pm 2.7^{\mathrm{c}}$ \\
\hline HFD + 5\% cocoa & $14.39 \pm 2.0^{\mathrm{b}}$ & $26.97 \pm 1.8^{\mathrm{b}}$ \\
\hline HFD + 10\% cocoa & $14.46 \pm 1.0^{\mathrm{c}}$ & $25.8 \pm 1.05^{\mathrm{b}}$ \\
\hline
\end{tabular}

Significance is expressed at $\mathrm{p}<0.05$ using one way ANOVA test. Values which have different letters in each column differ significantly, while the difference among those with similar letters completely or partially is not significant.

\section{Organs Weight / Body Weight \% :}

Data presented in Table (3) showed the mean value of liver weight / body weight $\%$ of all treated groups had no significant differences $(\mathrm{P}>0.05)$ as compared to the value of the control - ve group. The lowest mean value of liver weight / body weight \% was recorded for the control +ve, while the highest mean value was recorded for group of rats treated with cocoa powder $(5 \%)$.
As for the mean value of kidney weight / body weight $\%$,, the lowest mean value was recorded for rats treated with cocoa powder $(10 \%)$ while the highest mean value was recorded for the control ve group. Regarding spleen weight / body weight rats treated with $5 \%$ or $10 \%$ recorded significant decrease in mean value compared to the value of the control + ve group, and closed with control -ve group. 
Biochemical and nutritional studies on cocoa powder and its effect on blood lipids in experimental rats

Table 2: Mean values \pm SD of organs weight / body weight $\%$ of control rats and treated groups $(n=36)$.

\begin{tabular}{|l|l|l|l|}
\hline $\begin{array}{l}\text { Parameter } \\
\text { Group }\end{array}$ & Liver & kidney & spleen \\
\hline Normal control ( v-) & $4.38 \pm 3.8^{\mathrm{a}}$ & $1.56 \pm 0.31^{\mathrm{a}}$ & $0.41 \pm 0.22^{\mathrm{a}}$ \\
\hline Positive control ( v+) & $3.4 \pm 0.9^{\mathrm{b}}$ & $1.52 \pm 0.38^{\mathrm{ab}}$ & $0.51 \pm 0.16^{\mathrm{b}}$ \\
\hline HFD + 5\% cocoa & $4.05 \pm 0.79^{\mathrm{a}}$ & $1.32 \pm 0.13^{\mathrm{bc}}$ & $0.46 \pm 0.19^{\mathrm{a}}$ \\
\hline HFD + 10\% cocoa & $3.8 \pm 0.72^{\mathrm{b}}$ & $1.04 \pm 0.080^{\mathrm{c}}$ & $0.45 \pm 0.18^{\mathrm{a}}$ \\
\hline
\end{tabular}

Significance is expressed at $p<0.05$ using one way ANOVA test. - Values which have different letters in each column differ significantly, while the difference among those with similar letters completely or partially is not significant.

Biochemical Analysis :

Serum Cholesterol and Triglycerides :

As shown in Table (4) the mean value of serum (cholesterol and triglycerides) for the -ve control group was significantly decreased as compared to the control +ve. It could be observed that, rats reserved supplemented diet with (cocoa powder $5 \%$ or $10 \%$ ) recorded significant $(\mathrm{P}>0.05)$ decrease in the mean value of cholesterol and triglycerides compared to the control +ve group. The best results of the mean values \pm SD of cholesterol were recorded for rats reserved supplemented diet with (cocoa powder $10 \%$ ).

Table 3: Mean values \pm SD of serum cholesterol and triglycerides of control rats and treated groups $(n=36)$

\begin{tabular}{|l|l|l|}
\hline Group & Total Cholesterol( TC) & Triglycerides(TG) \\
\hline Normal control ( v-) & $128.18 \pm 2.2^{\mathrm{ab}}$ & $135.2 \pm 3.4^{\mathrm{c}}$ \\
\hline Positive control $(\mathbf{v}+)$ & $195.79 \pm 12.9^{\mathrm{b}}$ & $201.8 \pm 5.8^{\mathrm{a}}$ \\
\hline HFD + 5\% cocoa & $131.1 \pm 3.2^{\mathrm{a}}$ & $147.07 \pm 4.4^{\mathrm{ab}}$ \\
\hline HFD + 10\% cocoa & $129.1 \pm 2.1^{\mathrm{b}}$ & $138.4 \pm 4.6^{\mathrm{b}}$ \\
\hline
\end{tabular}

Significance is expressed at $p<0.05$ using one way ANOVA test. - Values which have different letters in each column differ significantly, while the difference among those with similar letters completely or partially is not significant.

\section{Serum Lipoprotein:}

It could be noticed from data in Table (4) that the mean value of HDL-c of control +ve group was significantly deceased $(\mathrm{P}<0.05)$ as compared to control - ve group. However, the mean value $( \pm \mathrm{SD})$ of LDL and VLDL- in +ve group increased significantly $(\mathrm{P}<0.05)$ as compared to control -ve and cocoa powder groups. The best result was recorded for rats fed on cocoa powder (10\%) which closed to the mean value of control -ve group. Concerning the mean value $( \pm \mathrm{SD})$ of LDL-c it was noticed that Control +ve group significantly increased $(\mathrm{P}<0.05)$ as compared to the control $-\mathrm{ve}$ and other cocoa powder groups. The best result was recorded for rats fed on cocoa powder $(10 \%)$.

Results also showed no significant differences $(\mathrm{P}<0.05)$ among cocoa powder groups in the mean value of VLDL. 
Suzan A. Saad

Table 4: Mean values $( \pm \mathrm{SD})$ of serum lipoproteins of control rats and treated groups $(n=36)$

\begin{tabular}{|l|l|l|l|}
\hline Group & HDL & LDL & VLDL \\
\hline Normal control (v-) & $83.08 \pm 12.9^{\mathrm{a}}$ & $76.8 \pm 8.5^{\mathrm{b}}$ & $33.03 \pm 1.09^{\mathrm{b}}$ \\
\hline Positive control $(\mathbf{v}+)$ & $59.4 \pm 11.6^{\mathrm{b}}$ & $101.92 \pm 5.1^{\mathrm{c}}$ & $40.37 \pm 1.15^{\mathrm{a}}$ \\
\hline HFD + 5\% cocoa & $77.1 \pm 3.2^{\mathrm{c}}$ & $78.07 \pm 2.6^{\mathrm{ab}}$ & $36.33 \pm 2.6^{\mathrm{ab}}$ \\
\hline HFD + 10\% cocoa & $80.36 \pm 9.1^{\mathrm{a}}$ & $74.71 \pm 2.1^{\mathrm{b}}$ & $35.6 \pm 0.92^{\mathrm{ab}}$ \\
\hline
\end{tabular}

- Significance is expressed at $p<0.05$ using one way ANOVA test.

- Values which have different letters in each column differ significantly, while the difference among those with similar letters completely or partially is not significant.

\section{DISCUSSION}

The observed reduction in LDL and TC levels may be attributable to flavonoids contained in cocoa and dark chocolate. Flavanols in cocoa are present as monomers, oligomers or polymers, better known as procyanidins, and generally are thought to inhibit cholesterol absorption as well as the expression of LDL cholesterol receptors (Matsui et al., 2005). The results are in agreement with Min et al. (2013) who demonstrated that consumption of high fat diet significantly increased body weight while consumption of cocoa powder significant decrease in body weight and induced body loss.

The present results are in line with Kollar et al. (2002) found that flavonoids significantly reduce the value of total cholesterol in the serum of hypercholesterolemic rats. However, relative variability in the nutritional properties of cocoa powder has been reported. This variability may be attributed to a number of factors, such as differences in genotype, maturity stage, postharvest handling and storage conditions, product quality and analytical procedures (Baba $e t$ al ., 2007). This observed reduction may be attributable to flavonoids contained in cocoa and dark chocolate. Flavan-3-ols in cocoa are present as monomers, oligomers or polymers, better known as procyanidins, and generally are thought to inhibit cholesterol absorption as well as the expression of LDL cholesterol receptors (Matsui et al., 2005).

The presently obtained fat and energy values for defatted cocoa were consistent with those reported elsewhere (Wan et al ., 2001). Consistently, in this study, chocolate feeding increased serum HDL-cholesterol and decreased triglycerides. Cholesterol had some increasing effect on total cholesterol and VLDL-cholesterol, but this effect did not reach statistical significance. In line with these results, serum total cholesterol has been shown to increase or remain unchanged as a result of cholesterol feeding in animals. Nicod et al. (2014) found that polyphenols from cocoa administered at a dietary dose moderately modulate intestinal inflammation but do not increase cholesterol secretion by intestinal cells or enhance HDL functionality .

Other studies in animal models of obesity and diabetes demonstrate the effects of cocoa extract in reducing serum and hepatic triglycerides. In a diet-induced obesity model of Wistar rats, ten weeks of cocoa extract supplementation (14 and 140 mg per kg body mass per day) revealed a significant decrease in serum and hepatic triglyceride content. Indeed, some human studies showed that administration of polyphenol-rich foods such as cocoa powder modulated and decreased LDL-C and increased HDL-C concentrations (Do ., 2010). 


\section{Biochemical and nutritional studies on cocoa powder and its effect on blood lipids in} experimental rats

A meta-analysis showed that short-term polyphenol-rich cocoa consumption (duration of intervention ranging from 14 to 126 days) decreased LDL-C by approximately $2.98 \mathrm{mg} / \mathrm{dL}$ and increased HDL-C by $1.78 \mathrm{mg} / \mathrm{dL}$ (Galli,2012). Basu et al. (2015) reported conventional lipid data from the present clinical trial showing that polyphenol-rich cocoa increased postprandial HDL-C . Crew et al. (2008) indicated that regular ingestion of dark chocolate may have no adverse effects on serum lipid profile, whereas others have suggested that intake of dark chocolate reduced serum LDL cholesterol and triglyceride (TG) levels (Engler et al., 2004; Grassi et al., 2005), and increased serum high-density lipoprotein (HDL) cholesterol measurements (Mursu et al., 2004).

Polyphenol-rich cocoa may have attenuated the postprandial rise in VLDL and chylomicron particles by interfering with their synthesis, which is typically increased in the presence of insulin resistance. Also, catechins have been shown to inhibit intestinal lipid absorption in animal and epidemiological studies (Lee et al ., 2003). Considering these clinical trials and the evidence in the present work, we contend that polyphenol-rich cocoa conferred cardio-protection by sustaining HDL concentrations and HDL concentrations for $6 \mathrm{~h}$ after a fast-foodstyle HF meal.

\section{CONCLUSIONS}

The present study indicated that consumption of cocoa powder and dark chocolate improved fraction lipid (total cholesterol, triglesrids and high density lipoprotein HDL) while lowered the mean value of body weight and LDL, VLDL. Therefore one can intake cocoa to decrease the risk of hyperlipidemia.

\section{REFERENCES}

Abuzaid A, Al-Menyar A, (2015) . Dyslipidemia, vascular atheroma and statins. Curr vasc pharmacol; 13(6):701-15.

Allen, R. R., L.; Carson, C.; Kwik-Uribe, E.M. Evans, J.W. and Erdman, Jr (2008). Daily consumption of a dark chocolate containing flavanols and added sterol esters affects cardiovascular risk factors in a normotensive population with elevated cholesterol. J. Nutr., 138(4): 725-731.

American Heart Association: Heart Disease and Stroke Statics:( 2004) Update. Dallas, TX , American Heart Association;( 2003).

Andres-Lacueva, C.; Monagas, M.; Khan, N.; Izquierdo-Pulido, M.; Arranz, S.; Valderas-Martinez, P.; ChivaBlanch, G.; Casas, R.; Urpi-Sarda, $\mathrm{M}$. and Lamuela-Raventos, R. (2013). Cardiooprotective effects of cocoa: Clinical evidence from randomized clinical intervention trials in human. Mol. Nutr. Food Res., 57(6):936-47.

Arts, I.C. and P. C. Hollman (2005). Polyphenols and disease risk in epidemiologic studies A. J. Clin. Nutr. 81:317-325.

Baba, S.; Natsume, M. and Yasuda, A., (2007). Plasma LDL and HDL cholesterol and oxidized LDL concentrations are altered in normo- and hypercholesterolemic humans after intake of different levels of cocoa powder. J. Nutr., 137(6):1436-1441.

Basu, A.; Betts, N.M.; Leyva, M.J.; Fu, D.; Aston, C.E. and Lyons, T.J. (2015). Acute cocoa supplementation increases postprandial HDL cholesterol and insulin in obese adults with type 2 diabetes after consumption of a high-fat breakfast. J. Nutr. 145, 2325-2332.

Blumberg, J.B.; Ding, E.L.; Dixon, R.; Pasinetti, G.M.; Villarreal, F. The science of cocoa flavanols: Bioavailability, emerging evidence, 


\section{Suzan A. Saad}

and proposed mechanisms. Adv. Nutr(2014), 5, 547-549.

Burstein, M. (2017). HDL cholesterol determination after separation high-density lipoprotein. J. Lipid. Res., 11: 583.

Colombo, M.L.; Pinorini-Godly, M.T. and Conti, A. (2012). Botany and pharmacognosy of the cacao tree. In: Paoletti, R.; Poli, A.; Conti, A.; Visioli, F., eds. Chocolate and health. Milan: Springer-Verlag Italia; pp. 41-62. DOI: 10.1007/978-88-470- 2038-2.

Di Renzo, L.; Rizzo, M.; Sarlo, F.; Colica, C.; Iacopino, L. and Domino, E (2015). Effects of diet. Med. J. Nutr. Metab., 8(1):51-60. DOI: 10.3233/MNM-140027.

Engler, M.B.; Engler, M.M.; Chen, C.Y.; Malloy, M.J.; Browne, A.; Chiu, E.Y. et al. (2004). Mietus-Snyder. Flavonoid-rich Dark chocolate improves endothelial function and increases plasma epicatechin concentrations in Healthy adults. Am. Coll. Nutr., 23: 197-204.

Eyre, H.; Kahan, R.; Robertson, R.M.; Clark, N.G.; Doyle, C.; Hong, Y.; Gansler, T.; Glynn, T.; Smith, R.A.; Tauber, K. and Thun, M.J. (2004). Preventing cancer, cardiovascular disease, and diabetes: a common agenda for the American Cancer Society, the American Diabetes Association, and the American Heart Association. Stroke 35(8).

Fossati, S.F. and R. Prancipel, (1982). Triglycerides determination after enzymatic hydrolysis .

Friedewald, W.T.; R.I. Leve and D.S. Fredrichson (1972). Estimation of concentration of low-density lipoproteins separated by three different. J. Clin.Chem., 18: 499S$502 \mathrm{~S}$.

Galli, C. (2012). Cocoa, chocolate and blood lipids. In: Paoletti, R.; Poli, A.; Conti, A.; Visioli, F. eds.
Chocolate and health. Milan: Springer-Verlag Italia; pp. 127-36. DOI: 10.1007/978-88-470-2038.

Goldstein, L.B.; Adams, R.; Becker, K.; Furberg, C.D.; Gorelick, P.B.; Hadamenos, G.; Hill, M.; Howard, G.; Howard, V.J.; Jacobs, B.; Leving, S.R.; Mosca, L.; Sacco, R.L.; Sherman D.G,; Wolf, P.A. and del Zoppo, G.J. (2001). Primary prevention of ischemic stroke: A statement for healthcare professional from the Stroke Council of the American Heart Association. Stroke, 32(1):280299.

Grassi, D.; Desideri, G.; Necozione, S.; Lippi, C.; Casale, R. and Properzi, G. (2008). Blood pressure is reduced and insulin sensitivity increased in Glucose-intolerant, Hypertensive subjects after 15 days of consuming high-polyphenol dark chocolate. J. Nutr., 138:16711676.

Grassi, D.; Lippi, C.; Necozione, S.; Desideri, G. and Ferri, C. (2005a). Short term administration of dark chocolate is followed by a significant increase in insulin sensitivity and a decrease in blood pressure in healthy persons. Am. J. Clin. Nutr., 81: 611-614.

Grassi, D.; Necozione, S.; Lippi, C.; Croce, G.; Valeri, L. and Pasqualetti, P. (2005b). Cocoa reduces blood pressure and insulin resistance and improves endothelium-dependent

vasodilation in Hypertensives. Hypertension, 46, 398-40.

Hammerstone, J.F.; S.A. Lazarus; A.E. Mitchell; R. Rucker and H.H. Schmitz (1999). Identification of procyanidins in cocoa (Theobroma cacao) and chocolate using highperformance liquid chromatography mass spectrometry. J. Agric. Food. Chem., 47: 490- 496. 
Hooper, L.; Kay, C.; Abdelhamid, A.; Kroon, P.A.; Cohn, J.S. and Rimm, E.B. (2012). Effects of chocolate, cocoa, and flavanols on cardiovascular health: A systematic review and meta-analysis of randomized trials. Am. J. Clin. Nutr., 95:740- 51.

DOI: 10.3945/ajcn.111.023457.

Kollar, P.; H. Kotolová; J. Necas; M. Karpísek; Kris- Etherton, P.M. and Keen, C.L. (2002). Evidence that the antioxidant flavonoids in tea and cocoa are beneficial for cardiovascular health. Curr Opin lipidol., 13(1):41-49.

Lee, K.W.; Kim, Y.J.; Lee, H.J. and Lee, C.Y. (2003). Cocoa has more phenolic phytochemicals and a higher antioxidant capacity than teas and red wine. J. Agric. Food Chem., 51: 7292-7295.

Mackay, J. and Mensah, G; (2004). The Atlas of Heart Disease and Stroke. The World Heart Organization. The diabetes Association, and the American Heart Association. Stroke

Matsui. N.; Ito, R.; Nishimura, E.; Yoshikawa, M.; Kato, M.; Kamei, M.; Mellor, D.D., Sathyapalan, T.; Kilpatrick, E.S.; Beckett, S. and Atkin, S.L. (2010). High-cocoa polyphenol-rich chocolate improves HDL cholesterol in Type 2 diabetes patients. Diabetic Med., 27(11):1318-1321. doi: 10.1111/j.1464-5491.2010.03108.x.

Cladera, M.; Costabile, A.; Childs, C.E.; Yaqoob, P.; Franch, A.; Castell, M. and Perez-Cano, F.J. (2015). Prebiotic effects of cocoa fibre on rats. J. Funct. Food, 19: 341-352.

Min, S.Y.; Yang, H.; Seo, S.G.; Shin, S.H.; Chung, M.Y.; Kim, J.; Lee, S.J.; Lee, H.J. and Lee, K.W. (2013). Cocoa polyphenols suppress adipogenesis in vitro and obesity in vivo by targeting insulin receptor. Int. J. Obes., 37: 584592.

Mursu, J.; Voutilainen, S.; Nurmi, T.; Rissanen, T.H.; Virtanen, J.K.; Kaikkonen, J. et al. (2004). Dark chocolate consumption increases HDL cholesterol concentration and chocolate fatty acids may inhibit lipid peroxidation in healthy humans. Free Radic Biol Med., 37: 1351-1359.

Nicod, N.; Chiva-Blanch, G.; Giordano, E.; Dávalos, A.; Parker, R.S. and Visioli, F. (2014). Green tea, cocoa, and red wine polyphenols moderately modulate intestinal inflammation and do not increase high-density lipoprotein (HDL) production. J. Agric. Food Chem., 62(10):2228-2232. doi: $10.1021 / \mathrm{jf} 500348 \mathrm{u}$.

Rein, D.; T.G. Paglieroni and T. Wun (2000). Cocoa inhibits platelet activation and function. Am. J. Clin. Nutr., 72: 30-35 .

Sanbongi, C.N.; Osakabe, M.; Natsume, T.; Takizawa, S.; Gomi, and T. Osawa (1998). Antioxidative polyphenols isolated from Theobroma cacao. Food. Chem. 46: 454-457.

Sentürk, T. and Günay, S. ( 2015). The mysterious light of dark chocolate. Arch. Turk Soc. Cardiol., 3(2):199207. DOI: $10.5543 /$ tkda.2015.70360.

Singleton, V.L. and Rossi, J.A.(2000). Colorimetry of total phenolics with Stampfer MJ, Hu FB, Manson JE, Rimm EB, Willett WC; Primary prevention of coronary heart disease in women through diet and lifestyle. N Engl J Med,343(1):1622.

Tanasescu, M.; Leitzmann, M.F.; Rimm, E.B.; Willett, W.C.; Stampfer, M.J. and Hu, F.B. (2002). Exercise type and intensity in relation to coronary heart disease in men. JAMA, 288(16):1994-2000. 


\section{Suzan A. Saad}

Tedgui, A. and Mallat, Z.( 2006). Cytokines in atherosclerosis : Pathogenic and Regulatory pathways. Physiol. Rev.; 86:51581.

Thompson, R.S.; D. Jacques; E. Haslam and R.J.N. Tanner (1972). Plant proanthocyanidins. Part I. Introduction; the isolation, structure, and distribution in nature of plant procyanidins J. Chem. Socie. Perk. Transd., 113: 13871399.

Wan, Y.; Vinson, J.A.; Etherton, T.D.; Proch, J.; Lazarus, S.A. and KrisEtherton, P.M. (2001). Effects of cocoa powder and dark chocolate on LDL oxidative susceptibility and prostaglandin concentrations in humans. Am. J. Clin. Nutr., 74(5):596-602.

Weisburger, J.H. (2000). Eat to live, not live to eat. Nutr., 6(9):767-773.

Wang-Polagruto, J.F.; Villablanca, A.C.; Polagruto, J.A.; Lee, L.; Holt, R.R.; Schrader, H.R. (2006). Chronic consumption of flavanol-rich cocoa improves endothelial function and decreases vascular cell adhesion molecule in hypercholesterolemic postmenopausal women. J. Cardiovasc. Pharmacol., 47(Suppl 2): S177-S186.

$$
\begin{aligned}
& \text { دراسات كميوحيوية وتغذوية علي مسحوق الكاكاو وتأثيره علي دهون الدم في جرذان التجارب } \\
& \text { قسم التغذية و علوم الأطعمة _كلية الاقتصاد المنزلي سلي - جامعة الأزهر }
\end{aligned}
$$

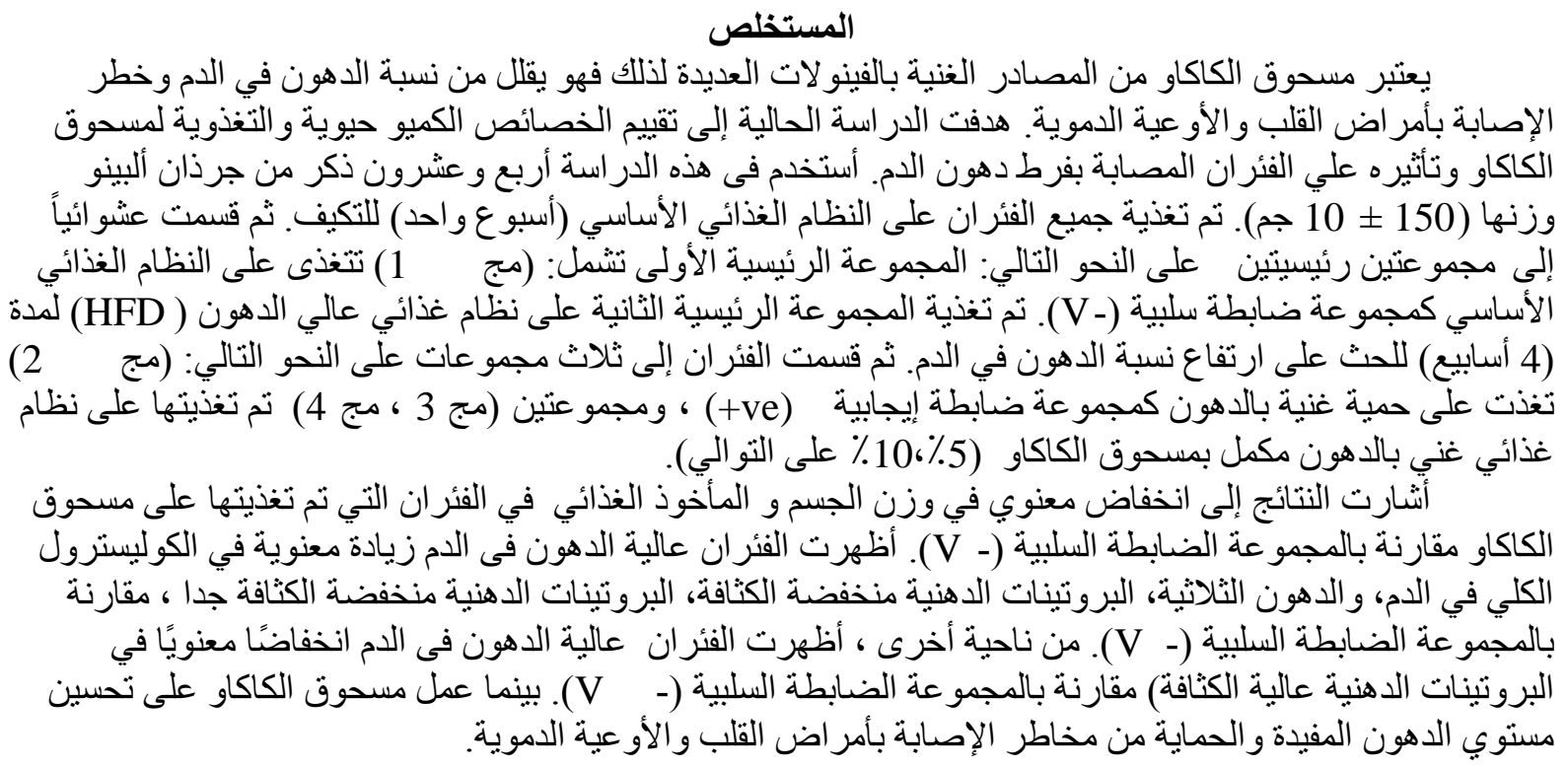

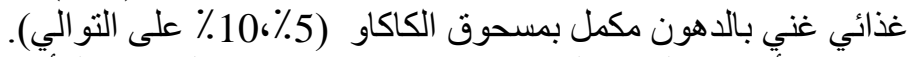

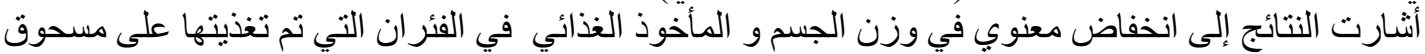

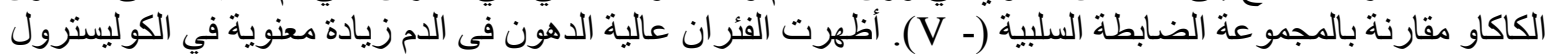

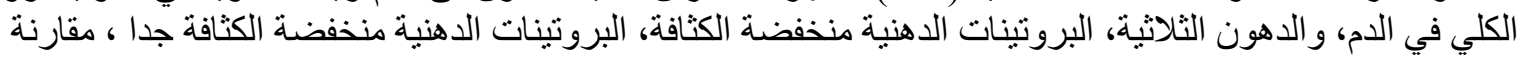

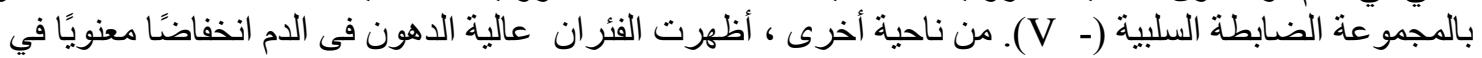

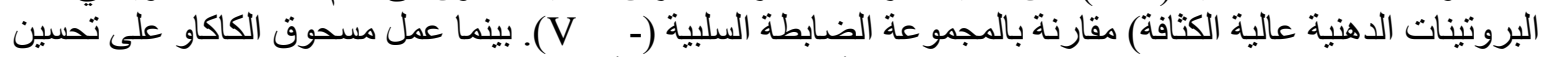
مستوي الدهون المفيدة والحماية من مخاطر الإصابة بأمر اض القارية القلب والأوعية الدموية. 